\title{
Prenatal Maternal Stress Due to Repeated Exposure to A Cold Environment Affects Development of Catecholamine Neurons in Rat Offspring: An Imunohistochemical Study
}

\author{
Keiko Ikemoto ${ }^{1-3^{*}}$, Teruko Uwano ${ }^{4}$, Akiyoshi Nishimura ${ }^{2}$, Katsuji Nishi ${ }^{3}$, Taketoshi Ono ${ }^{4}$ and Hisao $\mathrm{Nishijo}^{4}$ \\ ${ }^{1}$ Department of Psychiatry, Iwaki Kyoritsu General Hospital, 16 Kusehara, Mimaya-Machi, Uchigo, Iwaki, Fukushima, Japan \\ ${ }^{2}$ Department of Forensic Medicine, Health Bioscience Institute, Tokushima Graduate University, Tokushima, Japan \\ ${ }^{3}$ Department of Legal Medicine, Shiga University of Medical Science, Otsu, Japan \\ ${ }^{4}$ System Emotional Science, Graduate School of Medicine, University of Toyama, Toyama, Japan
}

"Corresponding author: Keiko Ikemoto, Department of Psychiatry, Iwaki Kyoritsu General Hospital, 16 Kusehara, Mimaya-Machi, Uchigo, Iwaki, Fukushima, 973-8555, Japan; Tel: +81-246-26-3151; Fax: +81-246-27-2148; E-mail: ikemoto@iwaki-kyoritsu.iwaki.fukushima.jp

Received date: Dec 09, 2014, Accepted date: Feb 17, 2015, Published date: Mar 24, 2015

Copyright: (C) 2015 Ikemoto $\mathrm{K}$, et al. This is an open-access article distributed under the terms of the Creative Commons Attribution License, which permits unrestricted use, distribution, and reproduction in any medium, provided the original author and source are credited.

\begin{abstract}
We examined the effect of maternal repeated cold stress (RCS) on the development of catecholamine neurons in offspring using 8-day-old offspring and tyrosine hydroxylase (TH) immunohistochemistry. RCS was loaded to pregnant rats between days 10 and 20 after fertilization. The frontal and cingulate cortices tended to contain fewer TH-immunoreactive (-ir) fibers, and the density of TH-ir varicosities with a large size (more than $7 \mu \mathrm{m}$ in diameter) was significantly $(p<0.05)$ less in rats prenatally exposed to RCS than controls. The locus coeruleus neurons of rat prenatally exposed to RCS displayed less TH immunoreactivity than controls. In the medullary C1/A1 catecholaminergic field, size of $\mathrm{TH}$-ir neurons was smaller and the quantity of $\mathrm{TH}$-ir fibers was less in prenatally exposed rats, although the difference was not significant. In the originating and projection fields of midbrain dopaminergic systems, we could not detect any differences in TH-ir structures between the two groups. These findings indicated that prenatal RCS impaired the development of catecholaminergic neurons, especially the noradrenergic neurons of pups.
\end{abstract}

Keywords: Cerebral cortex; Locus coeruleus; Medulla oblongata; Prenatal stress; Tyrosine hydroxylase; Dopamine; Noradrenaline; Development; Immunohistochemistry

\section{Introduction}

Prenatal stress is known to affect the emotional and behavioral development of offspring [1,2], and is thought to be a cause of mental disorders, including schizophrenia and depression [3]. Catecholamines (CA) are candidate neurotransmitters, being involved in emotion, behavior, and the pathogenesis of psychoses [4]. Furthermore, histological findings of catecholamine neuronal systems have been reported in postmortem brains of patients manifesting psychoses [5-7]. Based on these reports, morphological changes in the offsprings of prenatally stressed rats were hypothesized.

The present study investigated the affect of maternal repeated cold stress (RCS), the physiological influence of which has been well studied in rats [8-11], on the development of CA neurons in offspring using tyrosine hydroxylase $(\mathrm{TH})$ immunohistochemistry $[12,13]$.

\section{Experimental Procedures}

The study adhered current RIGOR guidelines [14,15].

Two female Wistar rats were randomizely selected for loading RCS between day 10 to 20 following fertilization. The treatment group was composed of the total of 24 pups (prenatally RCS rats) borne and fostered by the RCS- loaded mother rats. Another female Wistar rat was randomizely selected, and 10 pups borne and fostered by the latter mother rat composed the control group.

The SART (specific alteration of rhythm and temperature) stress apparatus (modified M-9000 apparatus made by Advantec Toyo) consisted of a built-in heater and cooler that could be controlled by an adjustable self-timer. The size of the interior of the apparatus was 120 $\mathrm{cm}$ in height and $105 \mathrm{X} 65 \mathrm{~cm}$ in width [8]. The environmental temperature in this apparatus was altered from 24 to -3 at 1 cycle / $2 \mathrm{~h}$ from 1000 to 1800 hours by switching the heater and cooler and was kept at -3 from 1800 hours until 1000 hours the following morning [8]. This sequence was repeated four times between 1000 and 1800 hours. The lighting was maintained on a 12: 12 light-dark cycle (light, 0700 to 1900 hours; dark, 1900 to 0700 hours). RCS was loaded to 2 pregnant Wistar rats between day 10 and 20 after fertilization.

A total of 24 prenatally SART-stressed rats (prenatal RCS rats, = treatment group) and 10 control rats (= control group) were examined. At postnatal day 8 , under deep anesthesia with $10 \mathrm{mg} / \mathrm{kg}$ of sodium

pentobarbital (Nembutal, Dainippon Pharm.), each neonate rat was perfused through the cardiac ventricle with $5 \mathrm{ml}$ of saline $(0.9 \%$ of $\mathrm{NaCl}$ ) followed by $20 \mathrm{ml}$ of fixative containing $4 \%$ paraformaldehyde or $5 \%$ glutaraldehyde [12]. Thirty or $50 \mu \mathrm{m}$ thick cryostat coronal sections were made from each brain. Detailed procedures for $\mathrm{TH}$ immunohistochemistry have been described elsewhere [12]. Details of the production, characterization and specificity of $\mathrm{TH}$ antiserum have been described elsewhere [13]. Some sections were counterstained with neutral red. Neurons immunoreactive for TH were observed 
Citation: Ikemoto K, Uwano T, Nishimura A, Nishi K, Ono T, et al. (2015) Prenatal Maternal Stress Due to Repeated Exposure to A Cold Environment Affects Development of Catecholamine Neurons in Rat Offspring: An Imunohistochemical Study. J Neurol Neurophysiol 6: 271. doi:10.4172/2155-9562.1000271

Page 2 of 3

under a light microscope. The atlas by Hokfelt et al. [16] was used to determine the anatomical localization of TH-positive neurons.

Image analyses were performed using a software, Win ROOF (version 5.0, Mitani Corporation, Japan) and a self-made PC program to quantify the size and number of varicosities and neural fibers.

\section{Results}

Average body weights of 8-day-old pups were 13.6 $\pm 1.32 \mathrm{~g}(\mathrm{n}=10)$ for control rats and $9.90 \pm 1.54 \mathrm{~g}(\mathrm{n}=24)$ for prenatal RCS rats, and wet weights of the brain were $0.67 \pm 0.07 \mathrm{~g}(\mathrm{n}=10)$ for control rats and $0.66 \pm 0.06 \mathrm{~g}(\mathrm{n}=24)$ for prenatal RCS rats, but there were no significant differences in either body or brain weight $(\mathrm{t}$-test, $\mathrm{p}<0.05)$. Although there were some individual differences between the findings in RCS rats and control rats, some evident differences between the two groups were noted.

The frontal and cingulate cortices of prenatal RCS rats, especially layers II and III, contained fewer TH-immunoreactive (-ir) fibers than controls (Figure $1 \mathrm{~A}$ and $\mathrm{B}$ ), though there were no significant differences. In these areas, $\mathrm{TH}$-ir fibers demonstrated apparently less TH-ir varicosities (Figure 1C, D). Image analysis demonstrated that the density of large varicosities (more than $7 \mu \mathrm{m}$ in diameter) in the TH-ir fibers was significantly $(\mathrm{p}<0.05)$ less in prenatal RCS rats than in controls.

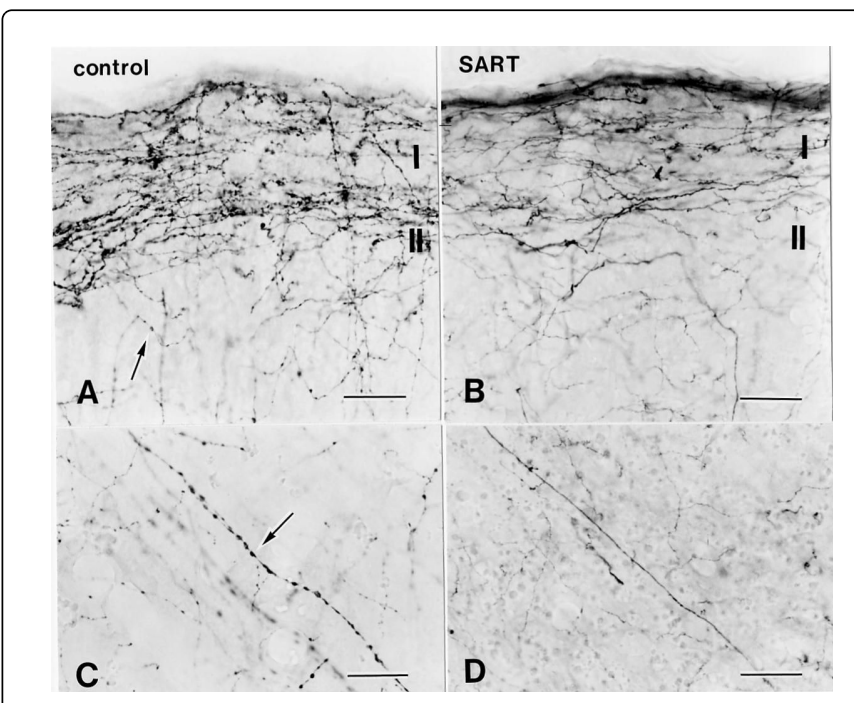

Figure 1: TH-immunoreactive (-ir) fibers in the frontal cortex, area 2 of 8-day-old pup following maternal exposure to RCS. (A, C) A control rat. (B, D) A prenatal RCS rat. The quantity of TH-ir fibers is lower in the prenatally RCS rat, especially in layers II and III. Cortical TH-ir fibers of RCS show a reduced number of large varicosities. An arrow indicates a varicose fiber of the control rat. Bar: $25 \mu \mathrm{m}$.

In the substantia nigra ( $\mathrm{SN}, \mathrm{A} 9)$ and ventral tegmental nucleus (VTA, A10), the originating nuclei of midbrain dopaminergic neurons, and in the striatum, their major projection field, there were no apparent differences in stainability or cellular sizes between the two groups. The locus coeruleus (LC), the originating nucleus of noradrenergic neurons, of the prenatal RCS rats showed less intense TH immunoreactivity (Figure 2A, B).

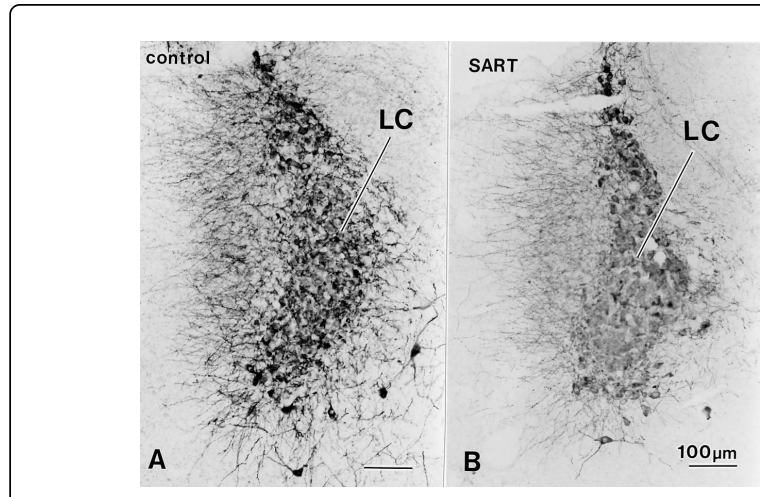

Figure 2: The LC (A6) neurons of prenatally RCS rats showed lower TH immunoreactivity.

In the medullary A1 / C1 catecholaminergic region (VLM: vetrolateral medulla) of the prenatal RCS rats, TH-ir neurons were likely to be smaller (the major axis: $11 \sim 30 \mu \mathrm{m}$ ) than those in the controls (the major axis: $15 \sim 33 \mu \mathrm{m}$ ), and TH-ir fibers were fewer as shown in Figure 3A, B. However, the comparison of the total areas of $\mathrm{TH}$-ir structures in A1 / C1 CA fields in each section by image analysis did not show any significant differences between the two groups $(\mathrm{p}<0.05)$.

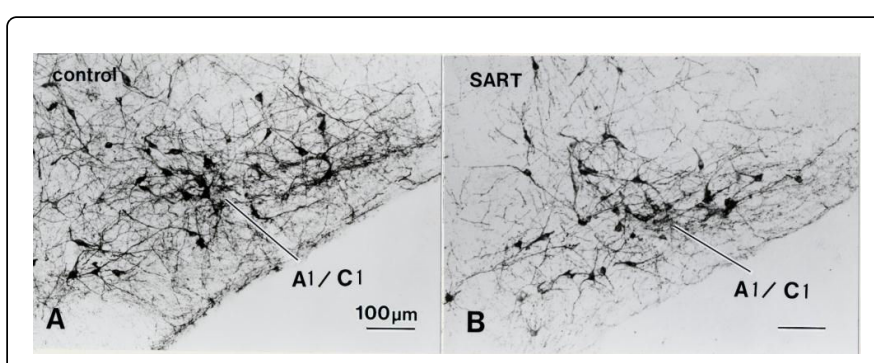

Figure 3: The medullary A1/C1 region (ventrolateral medulla) of an RCS rat demonstrated small TH-ir neuronal cell bodies and fewer TH-ir fibers.

\section{Discussion}

By examining TH-ir structures of 8-day-old pups, we demonstrated that maternal stress by repeated exposure to a cold environment affected the fetal development of CA neurons. This is the first morphological evidence showing the developmental influence of prenatal stress on the central nervous systems.

In the prenatal RCS group, the LC and VLM, the originating nuclei of noradrenalinergic neurons showed decreased $\mathrm{TH}$ immunoreactivity, smaller $\mathrm{TH}$-ir cell bodies and decreased $\mathrm{TH}$-ir neural fibers, suggesting that prenatal exposure to RCS affects the fetal development of noradrenalinergic neurons. The SN and VTA, the major originating nuclei of dopamine (DA) neurons, and the striatum, the projection field, did not show apparent morphological differences between the two groups. It suggested that prenatal RCS impaired the development of noradrenaline (NA) neurons rather than that of DA neurons in pups. 
Citation: Ikemoto K, Uwano T, Nishimura A, Nishi K, Ono T, et al. (2015) Prenatal Maternal Stress Due to Repeated Exposure to A Cold Environment Affects Development of Catecholamine Neurons in Rat Offspring: An Imunohistochemical Study. J Neurol Neurophysiol 6: 271. doi:10.4172/2155-9562.1000271

Page 3 of 3

Findings in the frontal and cingulate cortices of prenatal RCS pups, such as reduction on TH-ir fibers in all layers, especially in layers II III, morphologically coincide with findings of the NA neurons in the LC and VLM [17]. The reduction of large TH-ir varicosities (more than $7 \mu \mathrm{m}$ in diameter) in RCS pups implied impaired function of CA neurons. Such morphological changes in CA neurons of RSC pups do not transient change, but are likely to have long-term functional influences [18]. A recent report using restraint stress showed that intense prenatal stress reduced reactivity of NA neuronal systems for stress in adulthood [19]. Alteration of noradrenergic modulation of LTP in hippocampal slice by prenatal stress has also been shown [20].

Though numerous animal studies on prenatal stress using various methods including restraint stress have focused on metabolism and / or turn over of monoamines [18,19,21], to the authors' knowledge, there are no other studies focused on morphological changes in the CA neuronal systems.

Our recent studies demonstrated that prenatal RCS rats showed altered emotional development [2], and significantly smaller cingulate cortices on the coronal plane (unpublished data) similar to morphological findings in schizophrenia [22]. The cingulate cortex is likely to be a brain area vulnerable to prenatal stress, pathogenesis of psychoses, or a cause of developmental impairment.

In the present study, the analyses were limited only in 8-day-old pups. It remains to be elucidated whether these changes persist until an adolescent or adult stage. The genetic and/or epigenetic involvement producing the present findings should also be investigated.

\section{Acknowledgements}

This study was supported by Grants-in-Aid for Scientific Research from the Japan Society for the Promotion of Science.

\section{References}

1. Takahashi LK, Turner JG, Kalin NH (1992) Prenatal stress alters brain catecholaminergic activity and potentiates stress-induced behavior in adult rats. Brain Res 574: 131-137.

2. Tazumi T, Hori E, Uwano T, Umeno K, Tanabe K, et al. (2005) Effects of prenatal maternal stress by repeated cold environment on behavioral and emotional development in the rat offspring. Behav Brain Res 162: 153-160.

3. Mednick SA, Cannon TD, Barr CE, Lyon M. (1991) Longitudinal perspectives in schizophrenia research: Fetal neural development and adult schizophrenia, Cambridge University Press, Cambridge.

4. Toru M, Nishikawa T, Mataga N, Takashima M. (1982) Dopamine metabolism increases in post-mortem schizophrenic basal ganglia. Neural Transm 54: 181-191.

5. Akil M, Pierri JN, Whitehead R, Edgar CL, Mohila C, et al. (1999) Lamina-specific alterations in the dopamine innervation of the prefrontal cortex in schizophrenic subjects. Am J Psychiatry 156: 1580-1589.
6. Akil M, Edgar CL, Pierri JN, Casali S, Lewis DA (2000) Decreased density of tyrosine hydroxylase-immunoreactive axons in the entorhinal cortex of schizophrenic subjects. Biol Psychiatry 47: 361-370.

7. Benes FM, Todtenkopf MS, Taylor JB (1997) Differential distribution of tyrosine hydroxylase fibers on small and large neurons in layer II of anterior cingulate cortex of schizophrenic brain. Synapse 25: 80-92.

8. Hata T, Kita T, Higashiguchi T, Ichida S (1986) Total Acetylcholine content, and activities of choline acetyltransferase and acetylcholinesterase in brain and duodenum of SART-stressed (repeated cold-stressed) rat. Jpn J Pharmacol 41: 475-485.

9. Hori T, Fukuda M, Suzuki H, Yano S, Ono T (1993) SART stress effects on lymphocyte in the thymus and spleen of normal, adrenalectomized, and sympathectomyzed mice. Clin Immun and Immunopath 68: 243-255.

10. Kawanishi C, Fukuda M, Tamura R, Nishijo H, Ono T (1997) Effects of repeated cold stress on feeding, avoidance behavior, and pain-related nerve fiber activity. Physiol Behav 62: 849-855.

11. Tagoh H, Nishijo H, Uwano T, Kishi H, Ono T, et al. (1995) Reciprocal IL-1b gene expression in medial and lateral hypothalamic areas in SARTstressed mice. Neurosci Lett 184: 17-20.

12. Ikemoto K, Satoh K, Maeda T, Fibiger HC (1995) Neurochemical Heterogeneity of the primate nucleus accumbens. Exp Brain Res 104: 177-190.

13. Nagatsu I, Kondo Y, Inagaki S, Karasawa N, Kato N, et al. (1977) Immunofluorescent studies on tyrosine hydroxylase: Application for its axoplasmatic transport. Acta Histochem Cytochem 10: 494-499.

14. Lapchak PA (2013) Recommendations and practices to optimize stroke therapy: developing effective translational research programs. Stroke 44 : 841-843.

15. Landis SC, Amara SG, Asadullah K, Austin CP, Blumenstein R, et al. (2012) A call for transparent reporting to optimize the predictive value of preclinical research. Nature 490: 187-191.

16. Hokfelt T, Johansson O, Goldstein M (1984) Central catecholamine neurons as revealed by immunohistostochemistry with special reference to adrenaline neurons. In Handbook of Chemical Neuroanatomy. Vol. 2, Classical transmitters in the CNS, Part 1, A. Bjorklund, T. Hokfelt, ed. Elsevier; Ireland, pp.157-276.

17. Berger B, Verney C, Febvret A, Vigny A, Helle, KB (1985) Postnatal ontogenesis of the dopaminergic innervation in the rat anterior cingulate cortex (area 24). Immunocytochemical and catecholamine fluorescence histochemical analysis. Brain Res 353: 31-47.

18. Berger MA, Barros VG, Sarchi MI, Tarazi FI, Antonelli MC (2002) Longterm effects of prenatal stress on dopamine and glutamate receptors in adult rat brain. Neurochem Res 27: 1525-1533.

19. Hashimoto M, Watanabe T, Fujioka T, Tan N, Yamashita N, et al. (2001) Modulating effects of prenatal stress on hyperthermia induced in adult rat offspring by restraint or LPS-induced stress. Physiol Behav 73: 125-132

20. Grigoryan G, Segal M (2013) Prenatal stress alters noradrenergic modulation of LTP in hippocampal slices. J Neurophysiol 110: 279-285

21. Muneoka K, Mikuni M, Ogawa T, Kitera K, Kamei K, et al. (1997) Prenatal dexamethasone exposure alters brain monoamine metabolism and adrenocortical response in rat offspring. Am J Physiol 273: 1669-1675. 